\title{
Cop-like operon: Structure and organization in species of the Lactobacillale order
}

\author{
ANGÉLICA REYES ${ }^{1}$, ANDREA LEIVA ${ }^{1}$, VERÓNICA CAMBIAZO ${ }^{1}$, \\ MARCO A MÉNDEZ ${ }^{1,2}$ and MAURICIO GONZÁLEZ ${ }^{1}$
}

\author{
${ }^{1}$ Laboratorio de Bioinformática y Expresión Génica. INTA, Universidad de Chile \\ ${ }^{2}$ Laboratorio de Bioestadística (INTA). Universidad de Chile
}

\begin{abstract}
Copper is an essential and toxic trace metal for bacteria and, therefore, must be tightly regulated in the cell. Enterococcus hirae is a broadly studied model for copper homeostasis. The intracellular copper levels in $E$. hirae are regulated by the cop operon, which is formed by four genes: copA and $c o p \mathrm{~B}$ that encode ATPases for influx and efflux of copper, respectively; copZ that encodes a copper chaperone; and $\operatorname{cop} \mathrm{Y}$, a copper responsive repressor. Since the complete genome sequence for $E$. hirae is not available, it is possible that other genes may encode proteins involved in copper homeostasis. Here, we identified a cop-like operon in nine species of Lactobacillale order with a known genome sequence. All of them always encoded a CopY-like repressor and a copper ATPase. The alignment of the cop-like operon promoter region revealed two CopY binding sites, one of which was conserved in all strains, and the second was only present in species of Streptococcus genus and L.johnsonii. Additional proteins associated to copper metabolism, CutC and Cupredoxin, also were detected. This study allowed for the description of the structure and organization of the cop operon and discussion of a phylogenetic hypothesis based on the differences observed in this operon's organization and its regulation in Lactobacillale order.
\end{abstract}

Key terms: cop operon, CopY binding site, copper homeostasis, Enterococcus hirae, Lactobacillale order

\section{INTRODUCTION}

Copper $(\mathrm{Cu})$ is an essential micronutrient for all living organisms from bacteria to humans. $\mathrm{Cu}$ acts as a cofactor for several enzymes that carry out fundamental biological functions required for growth and development (4). However, excess of $\mathrm{Cu}$ is harmful to cells, resulting in cell death by their binding to essential cellular components (20). Due to this duality, $\mathrm{Cu}$ levels must be tightly controlled. In general, $\mathrm{Cu}$ homeostasis is regulated at three levels: uptake, intracellular distribution, and efflux. This regulation is achieved by the activity of conserved sets of cellular components that participate in these events (13).

Currently, the genomes sequence of multiple bacteria strains has become available in on-line databases. This information might be useful to identify genes associated to $\mathrm{Cu}$ metabolism in microorganisms and to inquire how gene reordering and gene structure divergence had occurred during operon evolution. Within Gram positive bacteria, one of the most extensively studied models for $\mathrm{Cu}$ homeostasis is Enterococcus hirae (Lactobacillale order) (16). The regulation of intracellular $\mathrm{Cu}$ in this strain is mediated by the cop operon that contains four genes: copA, copB, copy, and copZ. The CopA and $\mathrm{CopB}$ proteins are heavy metal $\mathrm{CPx}$ type ATPases and show a high sequence identity with the human Menkes and Wilson Cu ATPases (17). In E. hirae, CopA is required for uptake and CopB for efflux of $\mathrm{Cu}(15)$. In contrast, in other bacteria, 
functional studies of CopA orthologs show that this protein is involved in copper efflux (12). The copZ gene encodes a chaperone protein for $\mathrm{Cu}$, which receives the metal from CopA and delivers it to CopY (2). Recent studies have showed that higher $\mathrm{Cu}$ concentrations ( $>0.5 \mathrm{mM}$ of $\mathrm{Cu}$ ) downregulate CopZ by inducing its proteolysis (11). CopY acts as a $\mathrm{Cu}$-responsive repressor, thus when $\mathrm{Cu}$ increases in the media, CopY is released from the DNA, allowing transcription to proceed (2). Since the complete genome sequence of $E$. hirae is not available, we cannot discard that additional components might exist that play roles in $\mathrm{Cu}$ homeostasis.

In order to assess whether the mechanism of copper bacterial homeostasis is conserved in other species of the Lactobacillale order, we applied a bioinformatic methodology to identify the members of the cop operon. In doing so, we compared the sequence of cop operon genes to the complete genome sequence of other species of this order. Using this approach, we identified a cop-like operon in all the analyzed species. This operon contains a conserved core formed by a CopY-like repressor and a copper ATPase. The coplike operon also contains a similar CopY binding site, suggesting that it also is regulated by $\mathrm{Cu}$. In addition, in the analyzed species, we found candidate genes that might complement the functions of the cop operon in $E$. hirae $\mathrm{Cu}$ homeostasis.

\section{METHODS}

\section{Bacterial strain and sequence searches}

The complete genomes of the strains included in this study have been sequenced, and they belong to the Lactobacillale order. The sequences of cop-like genes were obtained using BLAST (Basic Local Alignment Search Tool) algorithm against the databases at The Institute for Genomic Research (TIGR) (http: //www.tigr.org). The E. hirae cop operon sequences used as template are indicated in figure 1. The sequences of cupredoxine (cuA) and $c u t C$ genes were found by searching for the term copper in the description of annotated genes.

\section{ClustalW analysis}

BioEdit software version 5.0.9 (7) was used to perform a multiple sequence alignment, using ClustalW option (19) with Protein weight matrix Blosum 62 and protein default options.

\section{Phylogenetic analysis}

We performed a Neighbor-joining analysis using the algorithm of Kimura of twoparameter distances (8). Statistical support of nodes was obtained by bootstrap analysis (1000 pseudoreplicates). All analyses were made using Mega 2.1 software (9). The 16S rRNA of Escherichia coli and Shigella flexneri were used as outgroup.

\section{CopY binding site}

We obtained a sequence $100 \mathrm{bp}$ upstream of cop Y-like gene start codon for 15 strains. We used ClustalW to perform alignment of the promoter region. Pairs of sequences were aligned according to the clade distribution of their $16 \mathrm{~S}$ rRNA tree (see Fig. 2).

\section{RESULTS AND DISCUSSION}

In this work, the term cop-like operon was used to denote sequences that appear as a cluster of at least two continuous cop genes with orthologs in E. hirae that were separated by less than $50 \mathrm{bp}$ and in the same transcriptional orientation. Using this definition, we detected the cop-like operon in 14 strains that corresponded to 9 species from the Lactobacillale order (Fig 1). The result of our sequence searches indicated the presence of a cop Y-like gene in all the strains, while in 13 strains we detected a copA-like gene, and a copZ-like gene was found in 5 species. A copB-like gene was detected in only one case. The apparent absence of a CopB-like protein $(\mathrm{Cu}$ efflux ATPase) in these nine species suggests that this function might be provided by paralogs 
of CopA ATPase, such as those found in $E$. faecalis, S. agalactiae, L. plantarum, and $L$. lactis (data not shown). Alternatively, we can not discard that CopA-like ATPase might have efflux function or have both are participating in uptake and efflux of $\mathrm{Cu}$ in the strains that possess only one gene coding for ATPase. Certainly, to clarify this point, functional analysis of CopA-like protein needs to be developed in the different strains. Further differences from the E. hirae cop operon were observed in S. agalactiae, which exhibited two copies of a cop-like operon, one of them containing cop Y-like, copA-like and copZ-like genes, and the other containing only cop Y-like and copA-like genes. In three species ( $S$. pneumoniae, $S$. mitis, and L. johnsonii), additional open reading frames (ORF) that formed part of the cop-like operon were also detected.

\begin{tabular}{|c|c|c|c|}
\hline Strains & cop-like operon structure & Promotor copY sequence & \\
\hline E. hirae ATCC 9770 & $-\infty \times 10$ & -65 GATPACAGTPGTA ATCTATTATCGAAGTTAAGTT ACAAA GTAATCGATGGAGGT & -10 \\
\hline E. faecalisV583 & $\rightleftarrows$ & -63 GACPACATTLGTAGTCGATAACC --- - TTGAACTCTTTTTTATTGATGAAGGAGGA & -12 \\
\hline L. johnsonii NCC 533 & $\rightleftarrows$ & -59 GTTGACAAGFTAAACTAAAAGTTATATGATACATTETAACGAAAGGAATATA & -4 \\
\hline L. plantarum WCFS & $\rightleftarrows \infty \times$ & -50 GTTIACGGTIGTAAACTACAGTTAATTTAATTCGAAGGGTGGTC -AAACCATTGGA & +5 \\
\hline L. lactis IL1403 & $\rightleftarrows$ & -51 GTTPACACGएGTAAACTTATCTTATGAAAATGAATCGGGAAAGGAGAAAAAATGAA & +5 \\
\hline S. mutans UA159 & $\rightleftarrows$ & -61 GTTGACAAATGTAGACAAAGAGGTTATAATGTATCTACAAATGTAl_ATGAAAGGAG & -6 \\
\hline S. agalactiae $2603 \mathrm{~V} / \mathrm{R}$ & $\rightleftarrows$ & -64 GTTPACA AATGTA GATTTATTT - - GCTAAAATTGGTTIACAAA GGTAAAT - - - - & -17 \\
\hline S. agalactiae $2603 \mathrm{~V} / \mathrm{R}$ & $\rightleftarrows$ & -67 GTTPACAATEGTAAACTTATCTTGAACATA - TTCGTTPACATCFGTAAACA--ACG & -15 \\
\hline S. agalactiae NEM316 & $\rightleftarrows$ & -64 GTTPACA AA TGTAGATTTATTT --GCTAAAATTGGTTLACA AA GTAAAT ------ & -17 \\
\hline S. pyogenes MGAS 315 & $\rightleftarrows$ & -70-TTPACA АA GTA GTTAAATTC--GTTATAATTAATT'ACA АA GTA МATATATTG & -18 \\
\hline S. pyogenes MGAS 8232 & $\rightleftarrows$ & -72-TTPACAAA & -18 \\
\hline S. pyogenes SF370 & $\rightleftarrows$ & -72-TT|TACAAATGTAGTTAAATTCGCGTTATAATTAATT"ACAAA\&GTAAATATATTG & -18 \\
\hline S. pyogenes SSI-1 & $\rightleftarrows$ & -70-TTPACAAA FGTAGTTAAATTC--GTTATAATTAATT ¿ACAAALGTAАATATATTG & -18 \\
\hline S. mitis NCTC12261 & $\rightleftarrows$ & -71 GTTGACAAA FGTAGATTTTAAGAGTATACTGATAATTGTAATT\&ACAAAFTA\&AT & -16 \\
\hline S. pneumoniae $\mathrm{R} 6$ & $\rightleftarrows$ & -65 ATTGACAAA & -10 \\
\hline S. pneumoniae TIGR4 & & -65 ATTGACAAALGTAGATTTTAAGAGTATACTGATGAGTGTAATT_ACAAATGTAGAT & -10 \\
\hline
\end{tabular}

Figure 1. Cop-like operon organization and putative CopY binding site in species of the Lactobacillale order.

Left side. The figure shows the organization of cop-like operon (arrows represent transcription start). S. agalactiae 2603V/R showed a second cop-like operon. Asterisk (*) indicates the names of genes in the cop operon of E. hirae and in cop-like operon from the other species. Right side. The promoter cop $\mathrm{Y}$ sequence containing putative CopY binding sites. Open boxes indicate consensus sequences for the 15 strains (10 species). The numbers at both sides of the promotor copY sequence indicate the position of nucleotides with respect to the first codon of CopY.

The Genebank access number of each of the cop-like operon genes are indicated from left to right for each strain: E. hirae: CAA86835.1, AAA61835.1, AAA61836.1, CAA86836.1; E. faecalis V583: AAO80160.1, AAO80161.1, AAO80162.1; L. johnsonii NCC 533: AAS09780.1, AAS09781.1, AAS09782.1, AAS09783.1; L. plantarum WCFS1: CAD65473.1, CAD65472.1; $L$. lactis subsp. lactis Il1403: AAK04930.1, AAK04931.1, AAK04932.1; S. mutans UA159: AAN58178.1, AAN58179.1, AAN58180.1; S. agalactiae 2603V/R: AAM99290.1, AAM99291.1, AAM99292.1 and AAN00137.1, AAN00136.1; S. agalactiae NEM316: CAD46064.1, CAD46065.1, CAD46066.1; S. pyogenes MGAS315: AAM80099.1, AAM80098.1, AAM80097.1; S. pyogenes MGAS8232: AAL98255.1, AAL98254.1, AAL98253.1; S. pyogenes M1 GAS: AAK34463.1, AAK34462.1, AAK34461.1; S. pyogenes SSI-1: BAC63470.1, BAC63471.1, BAC63472.1; S. mitis NCTC12261: SMT0402, SMT0403, SMT0404; S. pneumoniae R6: AAK99443.1, AAK99444.1, AAK99445.1; S. pneumoniae TIGR4: AAK74868.1, AAK74869.1, AAK74870.1. 


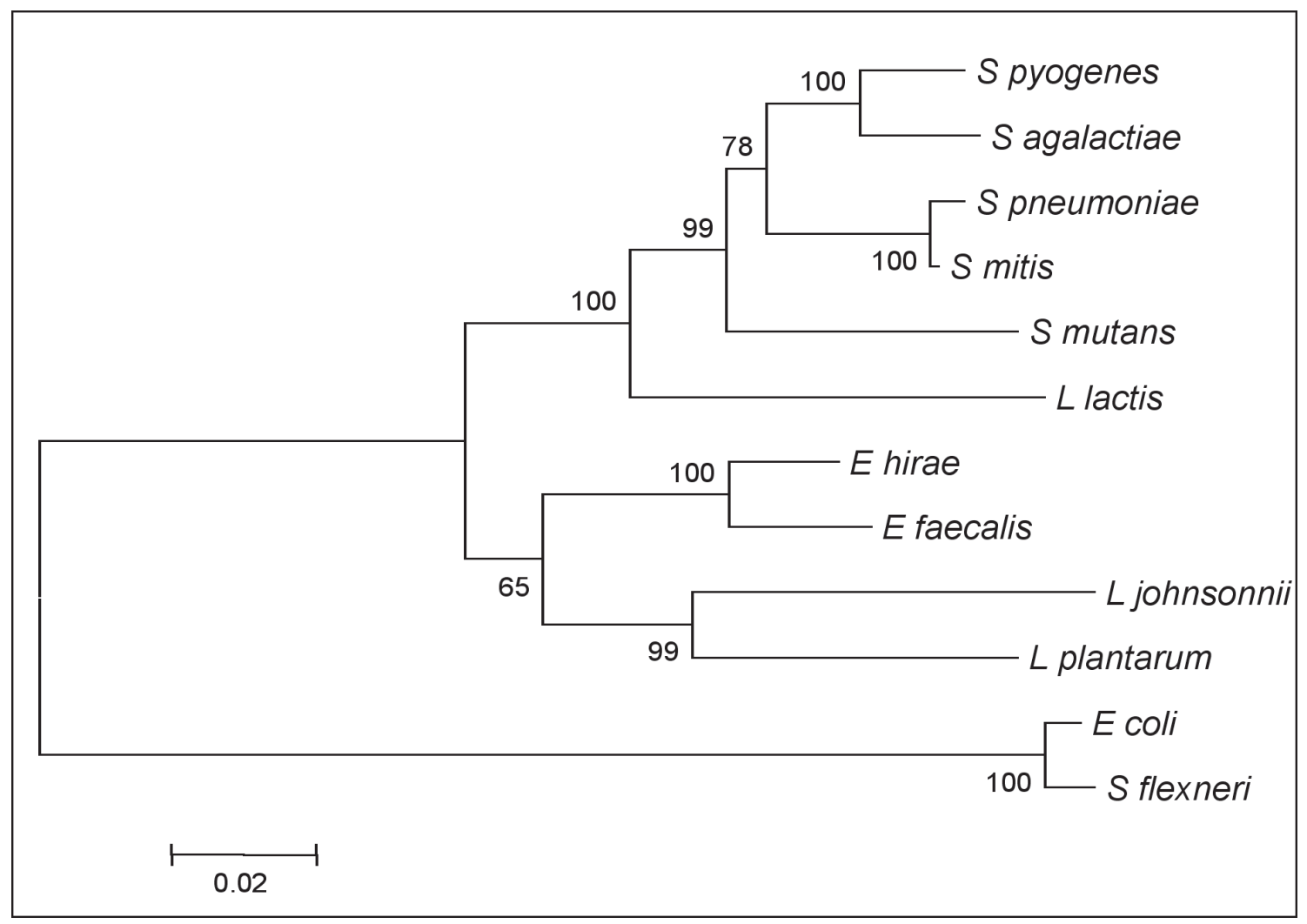

Figure 2. Neighbor-joining tree for the 16S rRNA sequences of Lactobacillale species. Bootstrap values are indicated on each node of the tree (1000 pseudoreplicates). Bar indicates number of substitution changes according to Kimura two-parameters distances. The Gene ID access of 16S rRNA sequences are: E. hirae AJ554205, E. faecalis 1199160, L. johnsonii 2742775, L. plantarum 1061905, L. lactis 1115945, S. mutans 2886073, S. pyogenes 1066450, S. agalactiae 1012735 , S. pneumoniae 933447, S. mitis 40204845.

We compared the organization of the cop-like operon in the 14 strains analyzed with that described for E. hirae cop operon; we found that the copY-like gene was at the beginning of the transcriptional units of all the strains. In 9 of them, the copA-like gene was down-stream from copY-like gene, while copZ-like gene either precedes or follows copA-like gene. These results indicate that a common position in the operon is found only for copY-like and copA-like genes among the strains of the Lactobacillale order, whereas a higher variability in the position of the copZ-like gene was detected. A phylogenetic analysis considering the organization of the operon is presented below.
When we compared the identity of the proteins encoded by the cop-like operon with those of $E$. hirae, we found that the ATPases presented high identity scores (42\%-51\%) with the CopA protein of $E$. hirae, however, they showed low identity with CopB $(<36 \%)$. An exception was observed for L. plantarum: the ATPase encoded in its cop-like operon showed $56 \%$ sequence identity and $72 \%$ similarity with CopB ATPase and a lower identity level with CopA (33\%). Similarly, Stentz et al. (2000) (18) showed that in Lactobacillus sakei, the single ATPase in the cop-like operon (ATKB) has $56.2 \%$ identity to the copper efflux CopB ATPase of E. hirae. Just as the ATPase found in L. plantarum, 
ATKB presents the same CPH motif found in CopB instead of the CPC motif usually present in the majority of ATPases (15). The high percentage of identity between $L$. plantarum ATPase and E. hirae CopB-like protein suggest that in L. plantarum, the ATPase might play a role in efflux.

Among the four components encoded in the cop-like operon, CopZ-like protein showed the lowest percentage of identity (24\%-42\%), and it was detected in 5 of the 9 species (Fig 1). In every case, CopZ-like protein presented an $\mathrm{MxCxxC}$ metal binding motif, characteristic of $\mathrm{Cu}$ chaperones, at the N-terminus (10). Interestingly, in L. lactis, we identified an amino-acidic sequence that exhibits a $42 \%$ identity with CopZ of E. hirae, which have been annotated as a mercuric reductase (YieF). Considering that in L. lactis this gene is localized in a cop-like operon between copY-like and copA-like genes and it exhibited a high identity with the CopZ of $E$. hirae, we propose that this protein corresponds to a $\mathrm{Cu}$ chaperone.

Regarding the CopY-like protein detected in the species of Lactobacillale order, their percentage of identity with CopY of E. hirae ranged from 33 to $49 \%$. In all of the proteins, we detected the

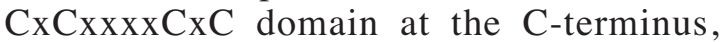
which is a conserved domain of $\mathrm{Cu}$ response transcription factors, such as Mac1 and Ace1 (3). In E. hirae, the consensus sequence TACAxxTGTA has been identified as the CopY binding site in the promoter region of the cop operon (cop box), which occurs two times in this species (14). Using the TACAxxTGTA consensus sequence, we found at least one cop box in all of the analyzed genomes (Fig 1), indicating that one of the E. hirae CopY binding sites determined by Portmann et al (14) is conserved in Lactobacillale species. Sequence alignment shows that 7 of the 8 bp near the -60 position from the start codon of the cop Y-like gene were maintained in all the strains. The other cop box described in E. hirae was present in all strains of Streptococcus genus and in $L$. johnsonii, approximately $22 \mathrm{bp}$ downstream from the first cop box. Thus, the presence of two binding sites, described for E. hirae seems to be a conserved feature of cop-like operon promoters of Lactobacillale species. Considering together the evidence of the conservation of the amino acid sequence of the CopY-like protein and its binding sites on the promotor region, we propose that the regulation of the cop-like operon is similar to that described for E. hirae.

In addition to the cop operon genes identified in $E$. hirae, other genes were detected in the cop-like operon after our analysis. In $S$. pneumoniae, $S$. mitis, and $L$. johnsonii we detected a gene encoding a protein whose $\mathrm{C}$-terminal domain was similar to the copper binding site present in cupredoxine $(\mathrm{CuA})$ protein. The cupredoxins, known as blue copper proteins, are small (10-20 kDa) soluble copper proteins whose role is to shuttle electrons from an electron donor to an electron acceptor in bacteria and plants (1, 5). Interestingly, in L. johnsonii, we found an extra ORF of unknown function between the copY-like and copA-like genes. The presence of these additional genes in the cop-like operon suggest that their expression is also under the regulation of CopY-like, and that they might complement the functions of $E$. hirae cop operon in $\mathrm{Cu}$ homeostasis. A component with putative function in copper homeostasis, annotated as cutC, was detected at a different chromosomal region in all the bacterial strains, except L. johnsonii and S. mutans. CutC is a cytoplasmic $\mathrm{Cu}$-binding protein (21) whose amino acidic sequence contains a pattern (M-X-X-M-X-X-X-M) similar to a putative $\mathrm{Cu}$-binding motif, and it has been suggested that CutC could participate in an efflux pathway for $\mathrm{Cu}$ (6). It will be interesting to test whether cutC is also present in the $E$. hirae genome, since it appears to be conserved among the Lactobacillale species.

With the purpose of examining the structure of the cop operon from an evolutionary point of view, we performed a phylogenetic analysis using their 16S rRNA sequences of the species analyzed above. The phylogenetic tree shows two major clades, one conformed by species of genus Streptococcus and Lactococcus, and the other by species of Lactobacillus and 
Enterococcus genus. Both clades presented terminal nodes with high frequency of occurrence (99-100\%) (Fig 2). We observed four different operon organizations among the species that form the first clade. The cop-like operon of $S$. pyogenes and $S$. agalactiae exhibited a collinear organization of copY-like, copA-like and copZ-like genes (Fig. 1 and Fig. 2). In $S$. pneumoniae and $S$. mitis, there is an insertion between cop $\mathrm{Y}$-like and copA-like genes, which is only present in this group, suggesting that it might be acquired from a common ancestor of this terminal node. $S$. mutans showed exactly the same operon organization as the $S$. pyogenes and $S$. agalactiae group, suggesting that the distribution pattern of copY-like, copA-like and copZ-like genes corresponds to an ancestral configuration of the first clade. In L. lactis, we observed a different operon organization (cop Y-like, copZ-like and copA-like) and only one CopY binding site. Since this species belong to another genus, the evaluation of these structural differences in an evolutionary context will depend on the comparison of other species of the genus. When we compared the cop operon in the second clade, we observed that there are practically no similarities in operon organization even within the same genus Enterococcus. However, more species of this genus are necessary to confirm the heterogeneity of operon organization within this clade. Regarding the conservation of the CopY binding site we observed that, independently of their relatedness, the majority of the species show two sites, suggesting that this attribute is a conserved character for all the analyzed species.

In summary, our results give insight on the conserved structural features of the cop operon among the Lactobacillale species and provide evidence for common regulatory mechanisms that coordinate the response to copper exposure in the cell. The operon exhibited a conserved core formed by a CopY-like repressor, a copper ATPase and a CopY binding site. In addition, the organization of genes inside the cop-like operon is in agreement with the existence of a common ancestor of the Streptococcus genus.

\section{ACKNOWLEDGEMENTS}

This work was supported by grants Fondecyt 1050235 and 1030618. AR was a recipient of a CONICYT fellowship.

\section{REFERENCES}

1. ARNESANO F, BANCI L, BERTINI I, THOMPSETT AR (2002) Solution structure of CopC: A cupredoxinlike protein involved in copper homeostasis. Structure (Camb). 10: 1337-1347

2. COBINE P, WICKRAMASINGHE WA, HARRISON MD, WEBER T, SOLIOZ M DAMERON CT (1999) The Enterococcus hirae copper chaperone CopZ delivers copper(I) to the CopY repressor. FEBS Lett. 445: 27-30

3. COBINE PA, GEORGE GN, JONES CE, WICKRAMASINGHE WA, SOLIOZ M, DAMERON CT (2002). Copper transfer from the $\mathrm{Cu}(\mathrm{I})$ chaperone, CopZ, to the repressor, Zn(II)CopY: Metal coordination environments and protein interactions. Biochemistry 41: 5822-5829

4. CRICHTON RR, PIERRE JL (2001) Old iron, young copper: From Mars to Venus. Biometals 14: 99-112

5. DE RIENZO F, GABDOULLINE RR, MENZIANI MC, WADE RC (2000) Blue copper proteins: A comparative analysis of their molecular interaction properties. Protein Sci. 9: 1439-1454

6. GUPTA SD, LEE BT, CAMAKARIS J, WU HC (1995) Identification of cutC and cutF (nlpE) genes involved in copper tolerance in Escherichia coli. J. Bacteriol. 177: 4207-4215

7. HALL TA (1999) BioEdit: A user-friendly biological sequence alignment editor and analysis program for Windows 95/98/NT. Nucl. Acids. Symp. Ser 41: 95-99

8. KIMURA M (1980) A simple method for estimating evolutionary rates of base substitutions through comparative studies of nucleotide sequences. J. Mol. Evol. 16: 111-120

9. KUMAR S, TAMURA K, JAKOBSEN IB, NEI M (2001) MEGA2: Molecular evolutionary genetics analysis software. Bioinformatics. 17: 1244-1245

10. LAMB AL, WERNIMONT AK, PUFAHL RA, CULOTTA VC, OHALLORAN TV, ROSENZWEIG AC (1999) Crystal structure of the copper chaperone for superoxide dismutase. Nat. Struct. Biol. 6: 724-729

11. LU ZH, SOLIOZ M (2001) Copper-induced proteolysis of the CopZ copper chaperone of Enterococcus hirae. J. Biol. Chem. 276: 47822-47827

12. OUTTEN FW, OUTTEN CE, HALE J, O'HALLORAN TV (2000) Transcriptional activation of an Escherichia coli copper efflux regulon by the chromosomal MerR homologue, cueR. J Biol Chem. 275: 31024-3102

13. PENA MM, LEE J, THIELE DJ (1999) A delicate balance: Homeostatic control of copper uptake and distribution. J. Nutr. 129: 1251-1260

14. PORTMANN R, MAGNANI D, STOYANOV JV, SCHMECHEL A, MULTHAUP G, SOLIOZ M (2004) Interaction kinetics of the copper-responsive CopY repressor with the cop promoter of Enterococcus hirae. J. Biol. Inorg. Chem. 9: 396-402

15. SOLIOZ M, ODERMATT A (1995) Copper and silver transport by CopB-ATPase in membrane vesicles of Enterococcus hirae. J. Biol. Chem. 270: 9217-9221

16. SOLIOZ M, STOYANOV JV (2003) Copper homeostasis in Enterococcus hirae. FEMS Microbiol. Rev. 27: 183-195 
17. SOLIOZ M, VULPE C (1996) CPx-type ATPases: A class of P-type ATPases that pump heavy metals. Trends Biochem. Sci. 21: 237-241

18. STENTZ R, LOIZEL C, MALLERET C, ZAGOREC M (2000) Development of genetic tools for Lactobacillus sakei: Disruption of the beta-galactosidase gene and use of lacZ as a reporter gene To study regulation of the putative copper ATPase, AtkB. Appl Environ Microbiol. 66: 4272-4278

19. THOMPSON JD, HIGGINS DG, GIBSON TJ (1994) CLUSTAL W: Improving the sensitivity of progressive multiple sequence alignment through sequence weighting, position-specific gap penalties and weight matrix choice. Nucleic Acids Res. 22: 4673-4680

20. URBANSKI NK, BERESEWICZ A (2000) Generation of $* \mathrm{OH}$ initiated by interaction of $\mathrm{Fe}^{2+}$ and $\mathrm{Cu}^{+}$with dioxygen; comparison with the Fenton chemistry. Acta Biochim. Pol. 47: 951-962

21. ZHU DY, ZHU YQ, HUANG RH, XIANG Y, YANG N, LU HX, LI GP, JIN Q, WANG DC (2004) Crystal structure of the copper homeostasis protein $(\mathrm{CutCm})$ from Shigella flexneri at 1.7 A resolution: The first structure of a new sequence family of TIM barrels. Proteins 58: 764-768 